\section{Distribution and status of Long-tailed Macaque (Macaca fascicularis aurea I. Geoffroy Saint-Hilaire, 1830) in Bangladesh}

\author{
Md. Kamrul Hasan ${ }^{1} \&$ Mohammed Mostafa \\ Feeroz $^{2}$
}

'Assistant Professor, 2 Professor, Department of Zoology, Jahangirnagar University, Savar, Dhaka 1342, Bangladesh Email: ${ }^{1}$ hasan_wildlifeju@yahoo.com, ${ }^{2}$ feerozmm@yahoo.com

Among the ten species of primates found in Bangladesh, five are macaques, namely, the Rhesus Macaque Macaca mulatta, the Pig-tailed Macaque Macaca leonina, the Assamese Macaque Macaca assamesis, the Stumptailed Macaque Macaca arctoides and the Long-tailed Macaque Macaca fascicularis. Except for the Rhesus, all other macaques are distributed in the northeastern and southeastern hill forests of Bangladesh. Only the Rhesus Macaques are found in both forested and non-forested areas. In Bangladesh, the population of primates are very low and some of them are Critically Endangered (IUCN 2000).

The fascicularis group of macaques comprises four species viz. Macaca fascicularis, M. mulatta, M. cyclopis and $M$. fuscata. Macaca fascicularis inhabits insular and peninsular Southeast Asia, from Bangladesh to the Philippines and Pulau Timor (Fooden 2006). Distribution of the subspecies M.f. aurea is restricted to Bangladesh and Myanmar. Sites in Bangladesh are the northwestern most geographical distribution of this subspecies. It is one of the Critically Endangered primate taxa of Bangladesh as well as in South Asia (Molur et al. 2003). There is little information on the distribution of Macaca fascicularis

Date of publication (online): 26 November 2010

Date of publication (print): 26 November 2010

ISSN 0974-7907 (online) | 0974-7893 (print)

Editor: Mewa Singh

Manuscript details:

Ms \# 02461

Received 20 May 2010

Final received 06 November 2010

Finally accepted 16 November 2010

Citation: Hasan, M.K. \& M.M. Feeroz (2010). Distribution and status of Long-tailed Macaque (Macaca fascicularis aurea I. Geoffroy Saint-Hilaire, 1830) in Bangladesh. Journal of Threatened Taxa 2(12): 1342-1344.

Copyright: () Md. Kamrul Hasan \& Mohammed Mostafa Feeroz 2010 Creative Commons Attribution 3.0 Unported License. JoTT allows unrestricted use of this article in any medium for non-profit purposes, reproduction and distribution by providing adequate credit to the authors and the source of publication.

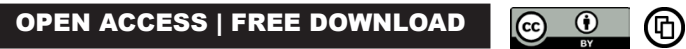

aurea in Bangladesh (Feeroz 2001) and no detailed study has been conducted on the status, distribution and demographics of this species. The aim of the study was to determine the present status and distribution of this local taxon.

Methods: Study Area: The occurrence of Long-tailed Macaques in the southeastern region of Bangladesh was confirmed by Feeroz in 2001. The study was conducted in all the existing and probable natural habitats of the Longtailed Macaque in this region and also in the Sundarbans. The southeastern region of Bangladesh comprises hill tracts, coastal areas and rivers. Some forested areas of this region, especially Cox's Bazaar division, or subjected to tidal activity. These regions provide some mangrove forest patches, which support the habitat of Long-tailed Macaque. Hence, the survey also included these regions.

Survey: A total of 20 field expeditions in the southeast and eight in the Sundarbans were conducted between December 2002 and January 2009 for the survey of Long-tailed Macaque (Fig. 1). Generally, the line transect method was used in all survey areas from dawn to dusk with a break of two hours at midday. Usually, a pathway used by local people inside the forest was used as a transect. The Sundarbans were extensively visited between 2002 and 2004 for studying various aspects of wildlife and their habitat (Feeroz \& Deodatus 2003; Feeroz 2004). Since it is impossible to make any line transect inside the Sundarbans because of its physical condition, we used a boat for survey and the river was considered as the transect line. In Teknaf, the survey was conducted inside the mangrove by boat during high tide and on foot during low tide. Surveys were conducted at different times of the day spread over different seasons.

As Long-tailed Macaques prefer coastal mangrove habitats, information was also collected from the local fishermen and then the occurrence of Long-tailed Macaques was confirmed by field survey in those habitats. GPS coordinates were recorded whenever any group of Long-tailed Macaques was found. Data on the location of the group, group size and composition were recorded in a pre-designed data sheet. In addition, data on habitat, home range and food availability were also recorded.

Results: Two groups of Long-tailed Macaques with five and three individuals were recorded from the mangrove forest patches of Naaf River bank (2054.02'E \& 92 ${ }^{0} 16.56$ ') (Image 1). Among these eight individuals five were adult males, two were adult females and one was juvenile (Table 1). The first group of $M$. $f$. aurea was recorded in 2005 and the second group was recorded in 2008.

In Fashiakhali (Chokoria Sundarbans), there were two groups of Long-tailed Macaque with 13 and 17 individuals (Feeroz 2001). During the study period not a single 


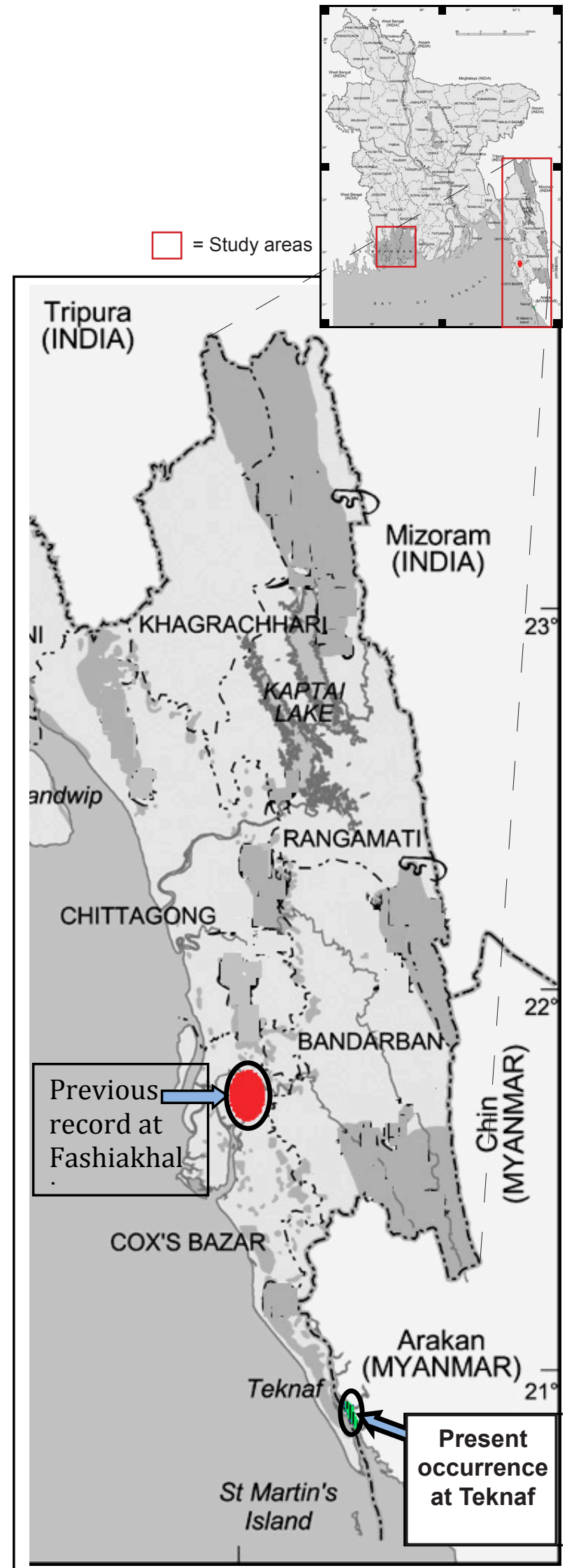

Figure 1. Distribution of Lion-tailed Macaque Macaca fascicularis aurea in Bangladesh individual was recorded from Fashiakhali coastal forest (Fig. 1). Currently the M.f. aurea groups occupy an area of 16.7ha of mangrove patches on the bank of Naaf River (Fig. 2).

Discussion: M.f. aurea was considered locally extinct from Bangladesh in the mid eighties. But in 1989, this species was again found in Fashiakhali, 100km away from its known habitat (Feeroz et al. 1995). This subspecies was recorded in Fashiakhali in 1997, but since then the groups have disappeared from the locality. Several primate surveys were conducted but this subspecies was not recorded till 2002. In 2003 we again located two groups, $5 \mathrm{~km}$ away from its known location. So we conducted a long term primate survey in the southeastern region to confirm the distribution of this subspecies. At present the coastal mangrove habitat in Fashiakhali is completely destroyed due to shrimp culture. All the Longtailed Macaque groups have probably been extripated from that area. In Teknaf the only surviving population of $M$. fascicularis aurea is now facing the threat of extinction. These eight individuals are probably the last individuals of M.f. aurea in Bangladesh. Habitat destruction for shrimp culture by clearing the mangrove forest patches, illegal logging, fuel wood collection and increasing population pressure are the major threats for their survival.

Moreover, this habitat is fragmented by the construction of a pathway towards the Jetty ghat (boat landing zone).

Table 1. Group size and composition of Macaca fascicularis aurea in Teknaf during the study period.

\begin{tabular}{|c|c|c|c|c|c|c|}
\hline \multirow[b]{2}{*}{ Location } & \multirow{2}{*}{$\begin{array}{c}\text { Group } \\
\text { no. }\end{array}$} & \multirow{2}{*}{$\begin{array}{l}\text { GPS } \\
\text { coordination }\end{array}$} & \multicolumn{3}{|c|}{ Group composition } & \multirow{2}{*}{$\begin{array}{r}\text { Total } \\
\text { indivi- } \\
\text { duals }\end{array}$} \\
\hline & & & $\begin{array}{l}\text { Adult } \\
\text { male }\end{array}$ & $\begin{array}{c}\text { Adult } \\
\text { female }\end{array}$ & Juvenile & \\
\hline \multirow{2}{*}{ Teknaf } & MF-1 & $\begin{array}{l}20^{0} 54.16^{\prime} \mathrm{N} \& \\
92^{0} 16.26^{\prime} \mathrm{E}\end{array}$ & 2 & 2 & 1 & 5 \\
\hline & MF-2 & $\begin{array}{l}20^{0} 54.02^{\prime} \mathrm{N} \& \\
92^{0} 16.56^{\prime} \mathrm{E}\end{array}$ & 3 & 0 & 0 & 3 \\
\hline
\end{tabular}

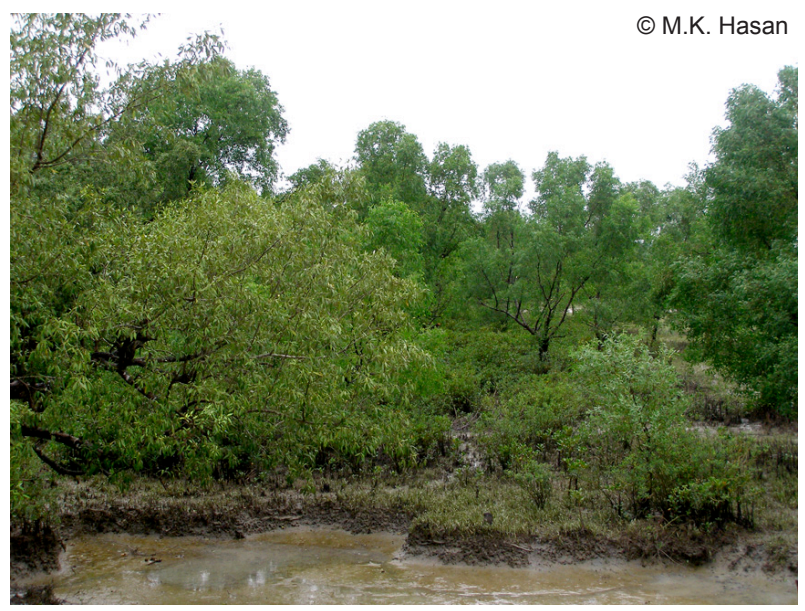

Image 1. Habitat of Macaca fascicularis aurea in Teknaf 


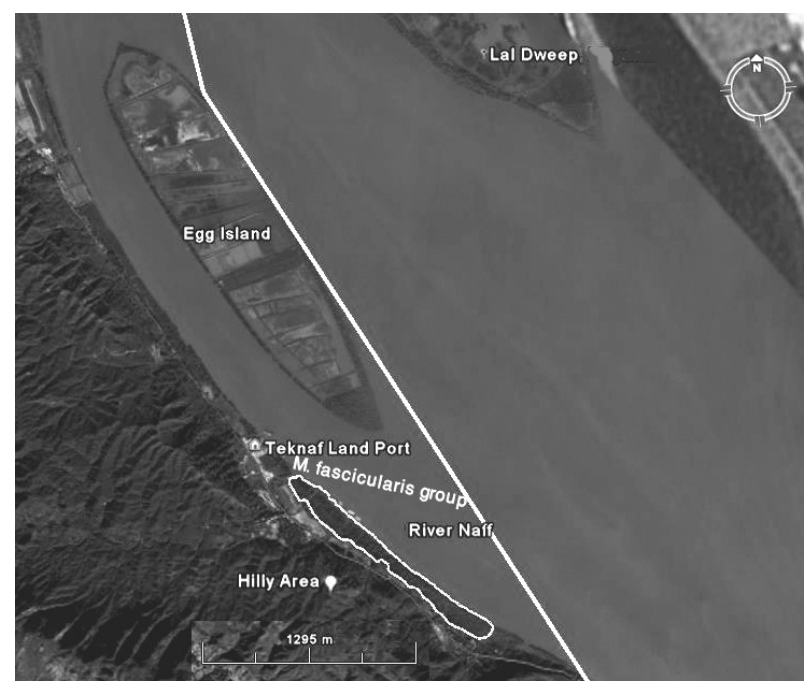

Figure 2. Location of Macaca fascicularis aurea group in Teknaf on Google Earth.

Local fishermen catch fish inside the habitat of this subspecies. Local people also graze their cattle inside the mangrove habitat. These regular activities cause a huge disturbance for the daily activity of M.f. aurea.

Teknaf land port is close to the habitat of this species. Moreover, the Naaf River bank is being used extensively as a boat landing zone. During the winter thousands of tourists use this area to go to St. Martin Island. Every year the construction of many new boat landing zones has been fragmenting the existing habitat as well as increasing the disturbance to the species.

Local information suggested that till 1990 there was a healthy population of Long-tailed Macaques on the banks of the river Naaf and in a small island called "Egg island or Dimer char" in Teknaf. Egg island is situated in the river Naaf and it is about $500 \mathrm{~m}$ away from the existing habitat of Long-tailed Macaques. Due to the shrimp cultivation in 1991-1992 on Egg Island, the farmers felled the entire mangrove vegetation on the Island. At present only the periphery of Egg Island has some mangrove plants and the rest is occupied by farmers and fishermen and no habitat of M.f. aurea exists. Local fishermen have confirmed the occurrence of Long-tailed Macaques on the adjoining Lal Deep Island of Myanmar.

The existing Long-tailed Macaque site in Teknaf is adjacent to the hill range where Rhesus Macaques are found. No Long-tailed Macaque was found in the hill range during the study period. Though the mangrove habitats in Teknaf have been destroyed very rapidly, Long-tailed Macaques did not shift to the hill range. The reason may be that more food is available in the mangrove habitat as compared to the hill range. The nearby island in Myanmar is only $500 \mathrm{~m}$ away from the Long-tailed Macaque habitat in Bangladesh. As Long-tail Macaques are good swimmers, they may have shifted to the island of Myanmar rather than the hill range of Bangladesh.

\section{REFERENCES}

Feeroz, M.M., M.A. Islam \& M.M. Kabir (1995). Status, distribution and conservation of non-human primates of Bangladesh. Kyoto University, Overseas Research Report of Studies on Asian Non-human Primates 9: 73-82.

Feeroz, M.M. (2001). Species diversity and population density of non-human primates in the north-east and south-east of Bangladesh. Ecoprint 8(1): 53-57.

Feeroz, M.M. \& F. Deodatus (2003). Wildlife training manual for basic ecology, wildlife management and survey technuques. Project component of Sundarban Biodiversity Management Plan (SBCP). Funded by Asian Development Bank (ADB), Global Environment Facility (GEF) and Government of the Netherlands.

Feeroz, M.M. (2004). Prey species abundance: pre-requisite for in situ tiger conservation in the Sundarban. Proceedings of the Seminar on "In situ conservation of tiger in the Sundarban, Bangladesh". Dharitri and CIDA, Bangladesh.

Fooden, J. (2006). Comparative review of fascicularis - group species of macaques (Primates: Macaca). Fieldiana: Zoology 107: 4

Hasan, M.K. (2003). Hoolock Gibbon of Bangladesh: Status and distribution. MSc Thesis. Department of Zoology, Jahangirnagar University, Dhaka, Bangladesh, ivx+165pp.

IUCN-BD (2000). Red Book of Threatened Mammals of Bangladesh. The World Coservation Union, 28pp.

Molur S., D. Brandon-Jones, W. Dittus, A. Eudey, A. Kumar, M. Singh, M.M. Feeroz, M. Chalise, P. Priya \& S. Walker (eds.) (2003). Status of South Asian Primates: Conservation Assessment and Management Plan (C.A.M.P.) Workshop Report, 2003. Zoo Outreach Organization Coimbatore, India, viii+432pp. 